\title{
New Interpretation of the Engraving Discovered at Mezhirich Upper Paleolithic Site
}

\author{
Eskander Baitenov ${ }^{1, *}$ \\ ${ }^{1}$ The Faculty of Architecture, Kazakh Leading Academy of Architecture and Civil Engineering, Almaty, \\ Kazakhstan \\ *Corresponding author. Email: bajte@mail.ru
}

\begin{abstract}
There have been suggested diverse interpretations of the engraving on a piece of mammoth's tusk which has been discovered at the Mezhirich upper Paleolithic site (Ukraine). The author suggests other version of the engraving's interpretation - the four elements that are placed frontally are the fragments of the "façade" of the so called first dwelling. The left plots on the engraving represent "facades" of the three other constructions. The form of the plate resembles almost fully the hypsometry of the Mezhirich cape. The placement of the facades on the plate is correlated in general with the location of the dwellings on the cape. The engraving is suggested to be closely connected with the rituals related symbols.
\end{abstract}

Keywords: Mezhirich, Upper Paleolithic Period, Dwelling erected from the mammoths' bones, Engraving, Mammoth's tusk, Paleolithic Art.

\section{INTRODUCTION}

Among plenty pieces of art that have been discovered at the Mezhirich Upper Paleolithic site ${ }^{1}$, the most unique one is an engraving that has been implemented on a piece of the mammoth's tusk (a plate of $11 \mathrm{sm} \times 21 \mathrm{sm})$. It reproduces four domelike figures that are placed along one line in the middle of the composition, they are interpreted hypothetically as the drawing of dwellings ("Figure 1") [1], [2]. By the period of the engraving discovering there had been excavated three dwellings erected from mammoths' bones at the specified site and as per Pidoplichko's suggestion (based on the variety of the discovered mammoth's bones) there should have been one more dwelling, which turned out to be so (see the layout of the site [3].

The engraving on the piece of mammoth's tusk (a plate) reproduces the drawing that represents four so-called stripes that are placed horizontally and four compact elements (the dwellings) are placed on the second one if we count from the

1. Mezhirich settlement is located on the middle course of the Dnepr river (Mezhirich village, Kanev district, Cherkask oblast, Ukraine) on the cape of the confluence of the Rosava and Ros' rivers, the Ros' river runs into the Dnepr river. bottom of the engraving. The specified four compact elements have V-shaped cut-outs and there are four circles within them. That was the basis for Pidoplichko to suggest that the drawing of the elements represent domed dwellings. Probably that was also the reason to reconstruct the four dwelling as the type of yaranga (skin tent) ("Figure 2"). The zigzags and chevrons reproduced on the lowest stripe Pidoplichko suggested as symbols of water. That is why there has been developed the conclusion that the engraving is the reproduction of the river and the Mezhirich site arranged along it. This piece (plate) of a mammoth's tusk is a wellknown sample of Paleolithic Art that has been mentioned many times in scientific papers (its detailed description included) [3]. There have been suggested other interpretations of the plate which are not related to layout of the site. K.N. Gavrilov has offered the version that the specified four elements are female symbols [4]. He justifies his concept as: if we turn the plate upside down so that the cuts out are pointed down we can see that the drawings resemble stylized reproductions of Paleolithic "Venuses". So we can't be absolutely sure that the drawing represents dwellings and even if so we are not able to determine the upper side and the bottom of it. 


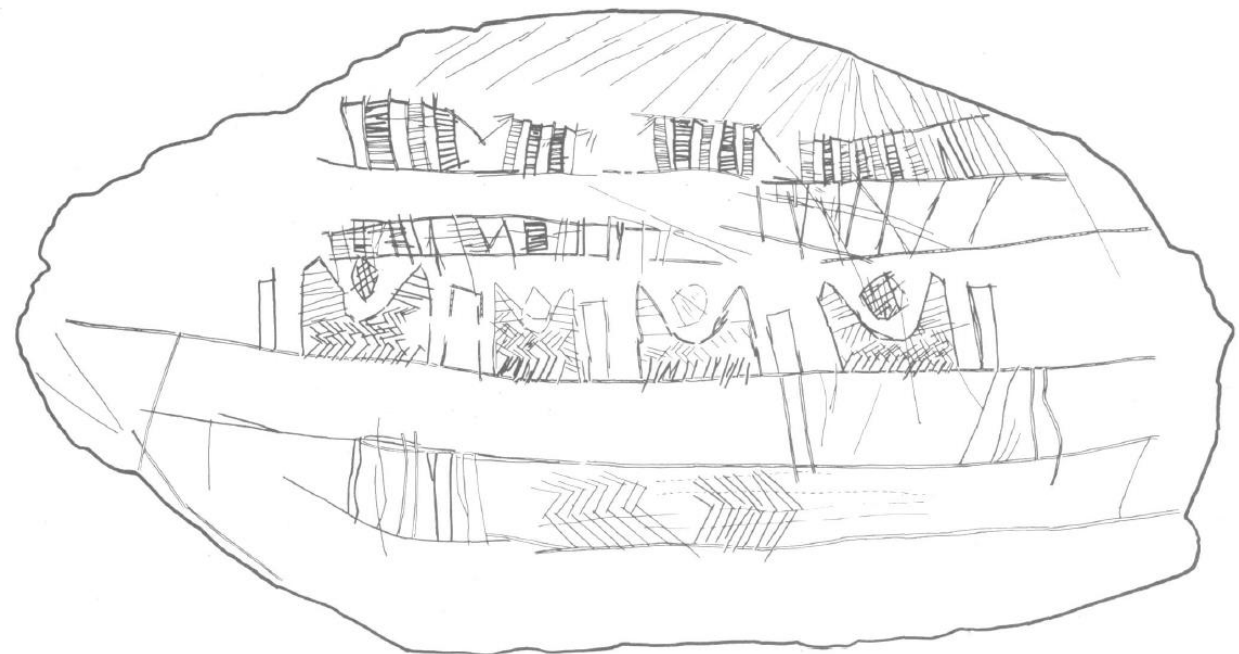

Figure 1 The "Map" of Mezherich settlement, reproduction was made on a piece of mammoth's tusk [5, fig. 42 on p. 292].

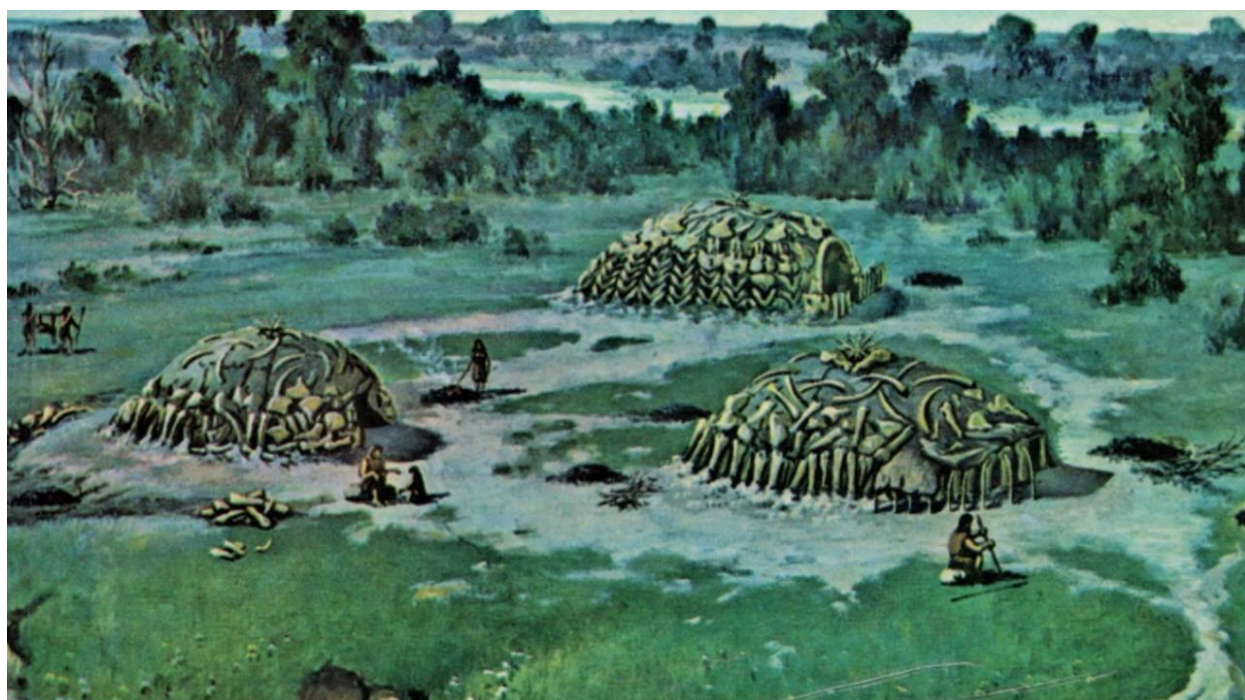

Figure 2 Reconstruction of the dwellings at the Mezherich site [2]

As we know, A. Marshak who has researched the trace-ology of the plate, has agreed with the hypothesis of E.G.Pidoplichko but he has offered his own suggestion as per the interpretation of the four elements that have circles above them. In line with his interpretation - the four elements are not dwellings but they are graphic fixation of the four calendar statement of the sun: during its springautumn and summer-winter solstices [5]. The drawing orientation offered by Pidoplichko and Marshak is confirmed by the fact that all the dwellings are underlined by one and the same line there is widely spread and well known Paleolithic Art device when the level of the ground is reproduced by the line (as well as in children's creative activity). Our further reasoning and suggestions are going to be based on the above orientation of the drawing.

\section{CONSTRUCTION BASIS OF THE FIRST MEZHIRICH DWELLING}

Taking into account the specifics of the engraving we can suggest other interpretation along with the existing ones (the "street" of four dwellings and the surrounding landscape, purely female symbols, calendar seasonal solstices). But first of all let's consider the reconstruction of the Mezhirich dwellings that was offered by E.G. Pidoplichko, especially the first one. As he suggested above, the dwellings resemble yaranga of the peoples of the North and so they might have been roofed up by the domes made of the rails that were covered by animals' skins which were attached and pressed down to them with the help of the bones of mammoths or other animals. The first 
dwelling (which is absolutely unique as per its "architecture") was based on the circle constructed from the mammoths' skulls which were dug into the ground by their maxillary parts, their frontal lobes were directed inside the circle. Another row of skulls was placed on the lowest row, they were installed as per their maxillary sides up, i.e. the skulls of these two rows were attached to each other by their back sides and foreheads. The outside of the construction which represented the circle made of two rows of mammoths' skulls was covered by the decorative siding made of lower jaws of mammoths that were inserted into each other vertically (from two and up to five items), the so called "herringbones". So as per reconstruction the outside of the dwellings had facing from the lower jaws of mammoths, some of the "herringbones" were topped with mammoth's skulls. ("Figure 3")

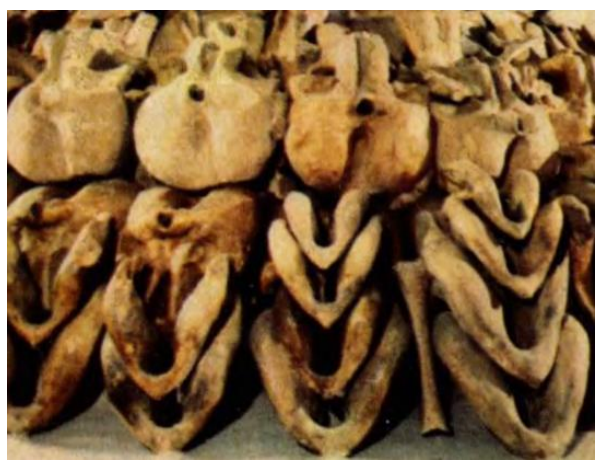

Figure 3 "Chevrons" implemented of lower jaws of mammoths with mammoth's skulls on their tops [1, fig.62].

J. Jelinek and L. Hanzalek, have hesitated as per both suggestions [6] that the dwellings had domes (we agree with them) and that some herringbones were topped with skulls which leaned on the circle made of the skulls. They have offered their own variant of dwellings' reconstruction, as per their concept the two rows of the circle made of mammoths' skulls can't be erected in the way when the round-shaped surface of the mammoths' foreheads and backsides are attached to another round-shaped surface of the mammoth's skulls, it doesn't meet the design requirements at all [6].

This looks clearly reasonable, but only in case the skull leans on another skull. As per our opinion the skulls of the upper row were installed in staggered way with the lower one, and moved a bit towards the center of the circle of the dwelling (deeper to the inside of the circle). In this case each skull of the upper row could have leaned on two skulls on the lower row and also it was supported from the outside by the lower jaws installed in sloping herringbones that were placed on ground base (outside facing of the dwellings).

The amount of the skulls of the lower row is twenty-five, and the amount of the herringbones is twenty-four, that aspect justifies indirectly our hypothesis that the skulls were installed in staggered way - each herringbone was erected between two skulls of the lower row. Then each skull of the upper row appears to be installed also between them, which it leaned on. So each skull of the upper row leaned on two adjacent skulls of the lower one. Moreover, the skulls of the lower rows were installed almost closely to each other - much closer to be compared to those of the other Mezhirich dwellings, which didn't have the second rows of installed skulls.

We can suggest that it was done in order to make the outside herringbones of the dwellings' facing be as close as possible and the "chevronzigzag" continuum to be developed. Thus in this case, each skull of the upper row surely leaned of two skulls of the second one, that provided its more stable position and that appeared to be the top of the according "herringbone" of the facing of the dwelling.

As per E.G. Pidoplichko's reconstruction, the "herringbones" were installed in the kind of a wall which has some slope. We suggest that the "herringbones" should have been installed on the outside ground base made also for the skulls' low row and the slope should have been less than that of E.G. Pidoplichko's reconstruction. His variant of reconstruction let him justify that the outside facing of dwelling was higher, which in turn increased the inside space that was useful for its accommodation for living. As per our suggestion the facing made of herringbones was a type of facing of the dwelling's blind area made of ground and implemented around it (almost the same way as it was discovered during the excavations). So, the "herringbones" could have been somehow the counterforts (the buttress) which supported the skulls of the upper row from the outside.

Also if there was considerable slope of the "herringbones" which were placed around the center of the dwelling, the spaces between them surely increased at the bottom, so there were installed tubular bones in some of them. At the same time, we should point out the crucial and principal aspect - such kind of construction must have been a self-bearing structure only, i.e. actually it must have been a round fence without any superstructure above that could have leaned on it 
(e.g. a dome). That aspect was also pointed out by J. Jelinek and L. Hanzalek (I do agree with them).

So, we don't agree with E.G. Pidoplichko who considers that the dwellings had domes but we support his concept (with our specifications) that the dwellings had outside facing made of lower jaws of mammoths that were installed into each other in the form of "herringbones" and that had skulls on their tops. We should point out that the closer we are to the bottom of the ruined construction the more exactly we can reconstruct its arrangement.

\section{AS RELATED TO THE INTERPRETATION OF THE "ENGRAVING" FROM MEZHIRICH}

The specified structures were reproduced on the second from the bottom stripe that was drawn on the piece of mammoth's bone (engraving on a plate) - the circles similar to skulls are inserted into "open" triangles which resemble "herringbones", which were developed from V-shaped lower jaws ("Figure 4"). Also, all these structures are separated from each other by vertical elements, which are correlated with the specified tubular bones installed between some "herringbones" - two big tibias, one femur and some other bones [2].

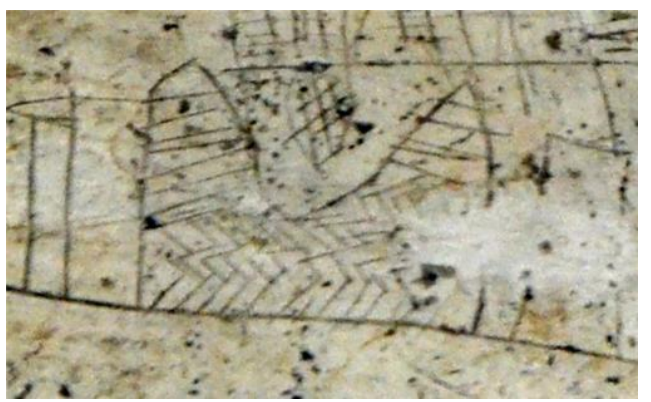

Figure 4 "Module" with the "opened triangle" and a circle within it. The fragment of the second from the bottom stripe of the Mezherich engraving.

So, the specified second stripe (of the engraving on a plate) would rather reproduce the façade of the first dwelling. Actually it is a part of the façade which has four "module elements" of the facing of the dwellings "basement" - each element represented the "herringbone" made of the lower jaws of mammoths that were topped by the mammoth's skull. In line with the dwellings' round layout, the "module element" was perceived frontally, but there might have also been the occurrence of the "quaternary code" [7]

The engraving wasn't a photographic copy of the first dwelling ${ }^{2}$ - it doesn't reproduce the exact image of the "herringbones" made of the lower jaws but the chevrons and zigzags of the four "module elements" show that they were interpreted as a kind symbolic and ornamental image of the "herringbone" which has a circle above it, there might be deeper meaning of the drawn elements (we'll consider them further). The second element (if to take it from the left) has a triangle above (not a circle) - some "herringbones" were not topped by skulls, they were crowned by mammoths' scapula (they are of triangle form).

Moreover, the three left horizontal stripes look as correlated with the "architecture" of the other three dwellings. Also we should point out the unique artistic specifics of the fourth dwelling, a part of its outside wall reproduces the following symmetric composition: a lower jaw installed in the way its chin part is upside and there are two chevrons that are placed from both side of it ("Figure 5"). Is it possible that the specified composition was re-interpreted and reproduced on the lower stripe placed on the engraving? Exactly this reproduction resembles "rhombus" engraved on the so-called "noisy" bracelet ("Figure 6") [8] and even on the phallic figures discovered in Mezin settlement (Ukraine) [9], which also has symmetrical elements of "herringbones" placed from both sides of it.
2. It is considered that the "ornament" of the facing of the basement in the kind of "herringbones" was covered by the ground (though it might have been opened some time, we hope to turn to this aspect in later papers). If the ornament of the walls was reproduced even in case they were covered by the ground, this fact justifies its great importance. 


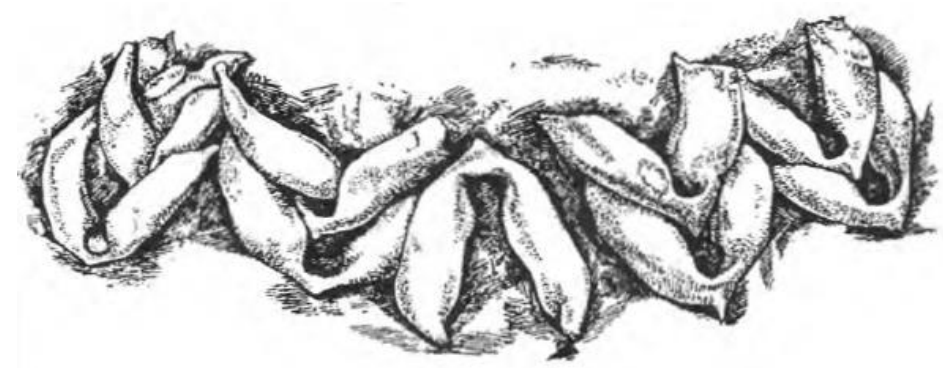

Figure 5 "Chevrons" and "zigzags" implemented of symmetrically installed lower jaws of mammoths that were the outside facing of the fourth Mezheich dwelling [10, p. 33, fig. 5,3].

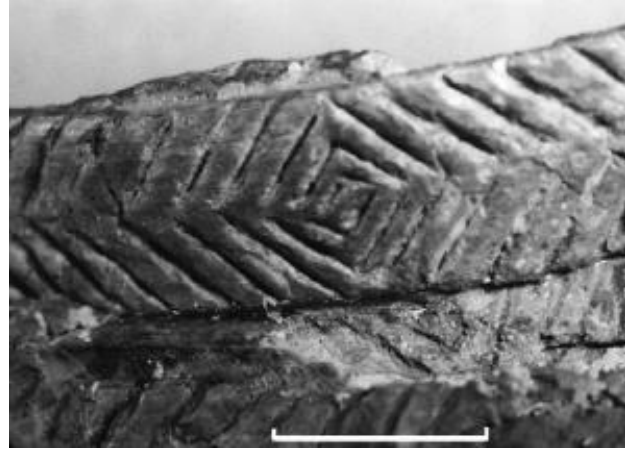

Figure 6 "Noisy" bracelet. Mezin settlement [19, fig. 14].

M.E. Gladkikh, who scrutinized Mezhirich settlement, has pointed out that there were some plots where groups of bones were discovered which were placed "symmetrically and by some rhythm", moreover, the symmetry took place even along the opposite outside walls as if the axis of symmetry was arranged through the center of the costruction (dwelling). Some tubular bones were installed vertically [10], [11] that is related to the left part of the lower stripe which has vertical lines, in our opinion. We should point out the importance of the symmetry for the Mezin culture - specific symmetric groups of bones were discovered in the circles of the second dwelling (as per V.Y. Sergin [9] and the third one as per E.G. Shovkoplyas [12].

The second from top "stripe" of the engraving looks as in line with the reproduction of the second dwelling - stylized drawing of vertically dug tubular bones, scapula bones and hip bones. The upper "stripe" has engraving of groups that consists of several thin vertical elements that are alternated by three wide plots.

It is clearly the third dwelling, which was located farther than the other dwellings, on the edge of the cape. The facing of the third dwelling is the most ruined one, but the composition of the bones is quite in line with the drawing of the upper stripe - quite amount of elbow, hip, tibia bones (vertical elements of the drawing), lower jaws ( $\mathrm{V}$-shaped tops of the wide plots). It should be pointed out that on the west side of the dwelling E.G. Pidoplichko specified three widened plots between the skulls through which diluvia flows penetrated (he considered the northern plot as the entrance) [2]. The widened plots between the skulls clearly match the wide plots on the stripe. Basically they might have been openings ("entrance holes") which were covered by flat bones (analogous to the "additional entrance" into the first dwelling which was arranged by installing of the V-shaped mammoth's jaw in the way its chin is upside [2]).

Further scrutiny of the engraving will foster more detailed reconstruction of the basement facing of the third dwelling. The vertical and horizontal lines are engraved on the right side of the second from the upper side (dwelling \#2) stripe and under the second stripe from the lower side, they obviously match the walls made of dug bones to arrange the main entrances into the dwellings.

The alternation of vertical elements and the transverse notches implemented on the two upper stripes look unclear. We consider the notches are not "birches" (trees) that make background, they might be the background between the vertically installed bones, or the ground of the "basement" (though there isn't any on the analogue elements of the lower stripe), or some remains of lines, or the traces of the marks of some rituals ${ }^{3}$.

The dwellings are placed above each other which rather means that they were located one behind another. Actually this is a sample of ancient views - somehow the panorama of bird's eye view reproduced on the flat surface, at that, without any landscape peculiarities - only the dwellings located on the cape - rounded form of the piece of the mammoth's bone should have been associated with

3. The ethnographic database of the peoples of Siberia is often used for the interpretation of Paleolithic culture, e.g. the notches on the metallic plate that was installed on the shoes of shaman's costume of the Ents and meaning the shin bone of the dear, symbolized bone marrow [13]. 
the form of the cape of the floodplain of Rosava river.

In the ancient times, the cape was bordered by the river's gulf from its west and south-west sides. The form of the lower part of the plate with the engraving might have been associated with the water's edge (the west) and the form of the upper left side of the plate (dwelling \#3) with the ancient ledge [2]. Then the sub-vertical lines placed above the upper stripe might have been gullies of the slope of cape which took place from the south-west to the north-east [14] and which occurred due to deluvial flows directed from the west to the east. [2].

\section{SYMBOLIC ASPECT}

Taking into account the opinion that the Vshaped jaws were associated with the "opened triangle [7] as the expression of the woman, we can suggest that the "module element" consisting of lower jaws inserted into each other with the skull of the mammoth on the top, i.e. "entering into them" is first of all the symbol of the act of copulation ${ }^{4}$, as it is also might have been reproduced on the drawing of the first dwelling of the considered engraving (see above).

But as per the reconstruction of the dwelling offered by Pidoplichko, mammoths' skulls were inserted by their back sides into the "herringbones" constructed from lower jaws of mammoths. The engraving of a mammoth applied on the mammoth's skull that was discovered in the first dwelling, was implemented in the similar way - stylized head of the mammoth was placed on the protruding $\mathrm{V}$ shaped cape of the nose holes of the mammoth [7]. And if to consider the engraving on the plate, the circle also "enters" the V-shaped element.

Then we can obviously suggest that the symbol of copulation was reproduced by the three specified

4. Composition of the upper jaw (skull) and the lower jaw is necessary for the act of chewing, this might have also been associated with copulation. Such kind of associations was obviously widely spread in traditional cultures. As per the views of the Chukkas the rocks of the sky from the four sides linked with the rocks of the earth and thus people were created from the pieces that appeared as the result of their friction [15]. Multiplicity of such actions, friction or striking of one object with another that resulted in the appearance of something new (mining of ocher or fire etc.) would have fostered the development of these chain of symbols into mental category. Topping of the "herringbone" made of lower jaws by the mammoth's skull was also one more step to the development of cosmogonic views that the sky and the earth copulated (the mammoth's skull is the masculinity and the jaws of mammoth is feminine). variants: "herringbones" constructed from lower jaws of mammoths with the inserted mammoth's skull, the drawing applied on the mammoth's skull and the engraving on the plate of mammoth's bone. Symbols duplication was typical for traditional cultures ("one object is also another one at the same time" [16]) and it took place up to the ethnographic period, it was remained in lamentations, spells and within fairy tales etc. Such kind of symbols were applied to all the process of dwellings' erection.

We should point out that incurved V-shaped lines of the four considered elements of the engraving is quite similar to the form of the cape of nose hole of the mammoth. We considered above the specifics of the filling in of the four elements of the "map", though chevrons and zigzags were reproduced there they didn't copy the form of the lower jaws in the "herringbones". They would rather reproduce some applied symbolic meaning.

In line with K.N. Gavrilov, who has studied the engraving, multi-row zigzags could have been "symbolic reproduction of life-giving fertilizing power" [4]. Moreover, Gavrilov reasonably suggests that the arched elements of the Eliseyevich settlement ("churinga") are symbols of feminine [The same place]. The specifics of the engraving from Mezhirich are that the symbol of copulation is directly reproduced in the "herringbones" constructed from the lower jaws of mammoths that were the facing of the first dwelling's basement. It is exactly the "herringbones" that are reproduced in the symbolic way as part of the façade of the first dwelling on the engraving. All these symbols provided and promoted magic reproduction of mammoths and sustainable development of the tribe in the broadest sense.

\section{CONCLUSION}

If we agree with the opinion that the horizontal chevrons applied on the two lower stripes of the considered engraving and resembling the drawing on the "noisy" bracelet from Mezin, the reproduction of the valve from Pshedmost (Check Republic) [4], and other similar drawings didn't copy the "décor" of the dwellings but transferred its "spirit", we should be confident to suggest that the engraving on a piece of mammoth's bone reproduces the fragments of the "facades" of all the four constructions. At the same time, we can't exclude that the placement of the bones and the considered engraving are the variants of the expression one and the same symbolism, i.e. the engraving didn't try to reproduce the dwellings 
naturally but it was the attempt to show the specifics of their graphic aspect and the "construction set" of the dwellings erected from the mammoths' bones. All the above should have supplemented each other in the expression of symbolic meanings within the frames of their specifics. The expressed symbols might have been accompanied by some actions such as: kind of soundtracks - spells or using drums (the skull with the applied engraving on and the "hammer" that were discovered in the first dwelling).

We should point out interesting specifics of the considered engraving - all the dwellings are drawn without any overlapping - the facades are reproduced in the king of high walls with figured facing made of bones. This aspect might help us to decipher - if the accumulation of bones inside the "dwelling" is the result of their roofs ruining or they might have been installed with some purpose [17]? We can suggest the latter in case there was not any overlapping at all. Moreover, we suggest that the layouts of the dwellings might have been of less importance as compared to the specifics of the outsides of the walls, the facing of all the four dwellings (otherwise there should have been drawn round figures as those of the petroglyphs of the Bronze Epoch which often reproduced the layouts of the construction). That is why there were reproduced the facades of dwellings and not the view from the above. And besides, as if the west façade that might have been the most impressive one: the plot to the left from the entrance of the first dwelling which reproduces "herringbones" with four skulls on the tops of them, also of the third dwelling - the plot with three holes, of the fourth dwelling - symmetric plot of its west façade. Moreover, there were the so-called "walls" in front of the entrances of the first and the second dwellings which were erected from the mammoths' bones dug into the ground vertically. It looks like these "walls" were reproduced on the right side of the engraving (they take such position if we look at the dwellings from the west).

So, the engraving is the most likely to be the reproduction of the "settlement", the suggestion has been shared by N.L. Korniets first (according to M.E. Gladkikh as D.V. Kepin informed). But we have some other interpretation of it to some extent. We specified above that the constructions reproduced on the "map" were not simple drawing from the life: both the "architecture" of the dwellings and the engraving on the plate are the strive to express one and the same generalized symbolic image. Despite the objective way of thinking, ancient people reproduced the most typical aspects of their activity. The exact situations (portrait similarity, individual circumstances etc.) were refracted through the multiple meanings' system of symbols. As the result of the process of their accumulation they supplemented and simultaneously unpacked the "moneybox" of archetypical categories, which in turn expanded the horizons of consciousness and sub-consciousness.

On the whole, the engraving on a piece of mammoth's bone from Mezhirich settlement is a sample of ancient people's perception of the "facades" of the dwellings and the general layout of the site, and also the expression of its "physical" and symbolic aspects. It might have been the world most ancient orthogonal projections of dwellings. As we know the well-known Tectiforms from Franco-Cantabria that were interpreted basically as a kind of dwellings might have had quite another origin [18].

\section{AUTHORS CONTRIBUTIONS}

This paper is independently completed by Eskander Baitenov.

\section{ACKNOWLEDGMENTS}

The author expresses his gratitude to Marcel Otte, Victor Sergin, Vadim Stepanchuk, Pavel Shidlovsky, Konstantin Gavrilov, Marina Komar, Martin Olive, Olga Soffer, Dmitriy Kepin for the shared scientific resources and the chance to discuss mutually some aspects.

\section{REFERENCES}

[1] I. G. Pidoplichko/ Late Paleolithic Mammoth's Bone Dwellings Located in Ukraine [Pozdnepaleoliticheskiye zhilishcha iz kostey mamonta na Ukraine]. The Academy of Science of the Ukraine Soviet Socialist Republic [Akademiya Nauk of Ukraine SSR], the Institute of Zoology [institut zoologii]. Publishing House "Scientific Thought" [Naukova Dumka], Kiev,1969. - p.135; p.137, fig. 58 http://irbisnbuv.gov.ua/ulib/item/UKR0008077

[2] I. G. Pidoplichko/ Mammoth's Bone Dwellings of Mezhyrich [Mezhirichskiye zhilishcha iz kostey mamonta]. Publishing House "Scientific Thought" [Naukova Dumka], Kiev, 1976. - p. 212, fig. 84; p. 102; p.96, fig. 
29; p.96, fig.29; p.120; p. 112, fig. 38 https://www.twirpx.com/file/2944783/

[3] Iakovleva L. L'art mézinien en Europe orientale dans son contexte chronologique, culturel et spirituel // L'anthropologie 113 (2009). p.708, Fig. 10; pp.713, 714, Fig. 14 https://www.sciencedirect.com/science/article/ abs/pii/S0003552109000909

[4] K.N. Gavrilov. The Woman-the Beast-the Ornament. Cultural Specifics of the Art of the Epigravet on the Russian Plane [Zhenshinazver'-ornament. Kulturnaya spetsifika V iskusstve epigravetta na Russkoy ravnine]. Collection of papers "Russian Archeology" [Rossiyskaya Arkheologiya], 2009, \#4, p. 74, pp. 76-78; fig. 5, A-1,2; pp. 77,78. http://naukarus.com/zhenschina-zverornament-kulturnaya-spetsifika-v-iskusstveepigravetta-na-russkoy-ravnine

[5] A. Marshack. Upper Paleolithic Symbol Systems of the Russian Plain: Cognitive and Comparative Analysis / CURRENT ANTHROPOLOGY Vol. 20, No. 2, June 1979. - c. 290

[6] J. Jelinek, L. Hanzalek. Essai de reconstruction de l'habitation pale' olithique de Mezhirich I. L'Anthropologie 91 (1), 1987. - p. 256

[7] E. Baitenov. Notes on the Unique Ocher Drawing Discovered at the Mezhyrich Paleolithic Site in Ukraine. L'anthropologie (2021). - c. 9, 12,10 https://doi.org/10.1016/ j.anthro.2021.102928

[8] Iakovleva L. L'ORNEMENTATION GEOMETRIQUE ET LA GEOMETRISATION DES FORMES DANS L'ART DU PALEOLITHIQUE SUPERIEUR EUROPEEN / IV colloque francoukrainien d'archéologie. Kiev, 2015

[9] V.Ya. Sergin. The Structure of the Mezin Settlement (Ukraine) [Stuktura Mezinskogo paleoliticheskogo poseleniya], Moscow, Publishing House "Science" [Nauka], 1987, p. 85 and others https://www.twirpx.com/file/2970438/

[10] M.I. Gladkikh. The Most Ancient Architecture According to the Archeological Sources of the Paleolithic Epoch [Drevrneyshaya arkhitektura po arkheologicheskim istochnikam epokhi paleolita]. Publishing House "Vita Antiqua" 1, 1999. - p.33, fig. 5 http://archaeology.kiev.ua/pub/gladkikh.htm

[11] M.I. Gladkikh. Household and Cult Related Use of the Dwellings Erected of Mammoths' Bones [Bytovoye i kultovoye ispolzovaniye zhilishch iz kostey mamonta]. Kiiv, (Ukraine), 2003. Publishing House "Shlyakh" [Shlyakh], collection of papers "The Stone Age in Ukraine" [Kamenny vek Ukrainy] 2003, issue \#4. - p. 215

[12] I.G. Shovkoplyas. Mezin Settlement: as Related to the History of the Basin of the Middle Course of the Dnepr River During the Late Paleolithic Period [Mezinskaya stoyanka: $\mathrm{k}$ istoree Crednedneprovskogo basseyna $\mathrm{v}$ pozdnepaleoliticheskuyu epokhu]. Kiyev, Publishing House "Scientific Thought" [Naukova dumka], 1965, p. 328.

[13] E.D. Prokofyeva. The costumes of Shamans of the Peoples of Siberia. Religious Views of the Peoples of Siberia in the XIX-beginning of the $\mathrm{XX}$ centuries [Shamanskiye Kostumy Narodov Sibiry/Religioznyye Predstavleniya Narodov Sibiry v XIX-nachale XX veka]. Collection of papers of the Museum of Anthropology and Ethnography (MAE), Leningrad: 1971, volume XXVII, p. 15. https://www.studmed.ru/prokofeva-edshamanskie-kostyumy-narodovsibiri_01974d0ac73.html

[14] V. Ya. Sergin. New Database on Household Complex 3 of Mezhirich Settlement of the Upper Paleolithic Period [Novyye dannyye o zhilishno-xozyaystvennom complekse 3 Mezhirichskogo poseleniya verhnego paleolita]. Collection of papers "Russian Archeology" [Rossiyskaya arkheologiya], 2013, \#2, p. 5.

[15] V. G. Bogoraz. Chukchi. Part 2, Religion. Leningrad, Publishing house of "Glavsevmorputy" [Glavsevmorputy], 1939, p. 42. https://na5ballov.pro/lib/relig/3783bogoraz-vg-chukchi-chast-2-religiya.html

[16] O.M. Freidenberg. Myth \& the Ancient Literature [Mif e literatura drevnosty]. - M.: The Headquarter of the Publishing House of the Oriental Literature [Glavnaya redaktseya vostochnoy literatury], 1976. - p. 23 
https://www.livelib.ru/book/1000820371-mifi-literatura-drevnosti-o-m-frejdenberg

[17] K.N. Gavrilov. "Dwellings" of the AnosovMazin Type: Origin and Interpretaion [Zhilisha Anosovsko-Mezinskogo tipa: proishozhdeniye e interpretatsiya]. Collection of papers "Stratum plus", 2015, \#1, p. 200. https://www.eanthropology.com/Katalog/Arheologia/STM_ DWL_EXQY_HuqjUNczPgbj.aspx

[18] E. Baitenov. Notes on Tectiforms: Experience of Interpretation, Context. L'anthropologie , Volume 124, Issue 3, 2020 https://www.sciencedirect.com/science/article/ abs/pii/S0003552120300601

[19] L. Iakovleva. Mezinian landscape system (Late Upper Palaeolithic of Eastern Europe) / Quaternary International 412 (2016). - Fig. 14.

https://www.researchgate.net/publication/2838 94683_Mezinian_landscape_system_Late_Up per_Palaeolithic_of_Eastern_Europe

http://www.ra.iaran.ru/?page_id=2516\&lang=r $\mathrm{u}$ 